\title{
Ways to address the challenges of a modern medical curriculum: Living academic medicine at the University of Split, School of Medicine
}

\begin{abstract}
Ivica Grković ${ }^{1}$, Damir Sapunar ${ }^{1}$, Matko Marušić ${ }^{2}$
${ }^{1}$ Department of Anatomy, Histology and Embryology, University of Split School of Medicine, Split, Croatia

${ }^{2}$ Department of Research in Biomedicine and Health, University of Split

School of Medicine, Split, Croatia

Corresponding author:

Ivica Grković

Department of Anatomy,

Histology and Embryology

School of Medicine in Split

Šoltanska 2

21000 Split

Croatia

ivica.grkovic@mefst.hr

Structure of a modern medical curriculum should follow recommendations of professional bodies (like World Federation for Medical Education) in order to educate and train medical professionals equipped with problem solving/critical thinking skills entering a world of evidence-based medicine and demands of contemporary medical practices. Also, political and socio-economic realities in addition to traditional and cultural values should be taken into account in order to avoid creating an unsustainable program. Requests for curricular changes by the European Union Commission were used as a chance to shape our program into an original blend of traditional pre-clinical and clinical subjects with several vertically integrated subjects focusing on mastering clinical skills, professional attitudes, information management and critical as well as evidence-based reasoning and decision making. Reasons for introducing curricular changes in addition to detailed structure of current medical course at the University of Split School of Medicine is presented in this paper.
\end{abstract}

Tel.: + 38521557803

Fax: + 38521557811

Received: 3 January 2012

Accepted: 17 February 2012

Copyright (C) 2012 by

Academy of Sciences and Arts

of Bosnia and Herzegovina.

E-mail for permission to publish:

amabih@anubih.ba

\section{Introduction}

Medical education at the tertiary level has been in existence since 1979 in Split, initially as a branch of the University of Zagreb School of Medicine and since 1997, as an independent School of Medicine within the University of Split (1). Establishing and
Key words: Education, Medical, Curriculum, Contemporary. 
staff members have extensive international experience in (mainly US) centres of biomedical excellence, where high-level academic medicine is practiced. Hence, young academic trainees from Split mastered the "trade" from colleagues who were constantly trying to balance three principal missions of academic medicine: health care, research and teaching $(4,5)$. Upon their return to Split, young academics strived to incorporate those habits not only into their daily routine, but also into our medical curriculum, which was different and original from the commencement of the course. Recent requests for curricular changes by the European Union Commission (below) helped shape our program into a rather unique and original mixture of "old and new". Hence, in addition to the traditional pre-clinical and clinical subjects, our curriculum includes several vertically integrated subjects focusing on mastering clinical skills, professional attitudes, information management and critical as well as evidence-based reasoning and decision making (6).

\section{What are the main problems associated with the traditional medical curriculum?}

Everyone involved in biomedical education has an opinion about medical curricula. How many times have we heard that the "curriculum is overloaded", that there is an "overemphasis on the recall of facts at the expense of scientific reasoning", that there is "failure to integrate basic science with clinical practice", perhaps there is "failure to produce students capable of self- initiated learning and critical thinking" or sometimes that the medical curriculum is not "responsive to the evolving needs of society". It is fascinating that all of the abovementioned opinions and impressions are actually highlights of an article dealing with a need to reform medical curriculum published in 1933 (7)! More recently, several publications have dealt with the need for fundamental changes in the organisation of medical curricula in order to prepare modern medical professionals to cope with rapid expansion of scientific biomedical knowledge and modern diagnostic/therapeutic technology. These papers also reflect the needs and expectations of modern society and changing conditions of the health care delivery systems $(8,9)$. Accepting and appreciating habits of lifelong learning and mastering new information technologies are now also seen as a must in a modern medical curriculum. Numerous reports have been put together by the World Federation for Medical Education (WFME) (10) suggesting the following recommendations with regards to aims and content of medical education:

- balance of academic and practical professional competences (skills, attitudes and communication abilities) should be achieved,

- core curriculum should be supplemented by well defined optional content,

- focus should be on prevention of disease and promotion of health and well being, in addition to the acquisition of basic biomedical, psychosocial and clinical knowledge and skills,

- when planning educational programmes, health needs of society should be considered,

- curriciculum should be adaptable to changes in regard to the spectrum of diseases as well as to demographic changes with a significant part of the curriculum in the primary care sector,

- research methodology and electives should be part of the curriculum as well as training of teamwork skills,

- careful coordination of basic, research, general postgraduate, specialist and continuing medical education phases of education should be in place, 
- teaching skills and developments should be given the same credit as research activities of academic staff members,

- a central curriculum committee looking after the structure of integrated curriculum and select methods of education and examination should be established,

- medical education should be recognised in faculty budgets the same way as research activities. Similar recommendations were produced concerning the learning process and assessment methods in medical education (see tables in reference 10).

\section{Why is there resistance to changes?}

Although everyone understands and agrees that changes in medical education are necessary, few are prepared to incorporate the above recommendations in their curricula. The lack of initiative is driven perhaps by robust traditional and cultural as well as political and socio-economic realities. Strong factors most certainly include a built-in conservatism of staff members, shortage (or complete lack of) educational budgets in addition to inadequate supervision of educational programmes and lack of academic incentives for teaching activities. Despite these, in the last three decades numerous new approaches have been mastered and implemented (with various success) in many medical faculties worldwide. Perhaps the most recognizable form of reformed medical curricula is the so called Problem Based Learning (PBL) approach, in which "real case-based" scenarios are used as triggers for teaching anatomy, physiology, biochemistry, pathology (and other pre-clinical disciplines) while at the same time adding clinically relevant meaning, resulting in a more enthusiastic approach by students (11). In addition to this, both horizontal integration (between disciplines) and vertical integration (between basic and clinical sciences) are supposed to bring academics from different departments together and "force" them to work on the above-mentioned common goals. This, in addition to very early contact with clinical scenarios, is helping students to lose their perception of the medical curriculum being disjointed, fragmented and, particularly during first few years, detached from clinical situations/ patients.

\section{Recent changes to our curriculum could not be resisted}

The new curriculum at the School of Medicine in Split was designed in line with recommendations of the Committee of experts which assessed the situation in five regulated professions in the health sector in the Republic of Croatia (conducted from 7 to 10 July 2008) and in accord with the provisions of the Regulated Professions and Recognition of Foreign Professional Qualifications Act passed by the Croatian Parliament in 2009 (12). The key determinants of the new program are six years of study, 5500 hours of direct teaching and 360 ECTS points. The program includes 190 hours of elective courses in the first 4 years of the course (worth 14 ECTS points) and 640 hours (24 ECTS points) of clinical rotations, a total of 890 hours or 44 ECTS credits. Detailed composition, including all subjects and teaching hours of our curriculum, is presented in $\mathrm{Ta}$ ble 1 . Some of the above changes were close in line with curricular modifications introduced almost 10 year ago when the first major reconstruction was performed (13). 
Table 1 List of compulsory subjects and/or modules with hours of active teaching required and ECTS points allocated in the new program of Medicine in Split, Croatia.

\begin{tabular}{llll}
\hline YEAR 1 & \multicolumn{2}{l}{ Hours* } & \\
\hline Subject & Total & L+S+P & \\
\hline Medical Humanities I - Introduction to Medicine & 25 & $10+5+10$ & 2 \\
Medical Biology & 100 & $34+34+32$ & 9 \\
Medical Physics and Biophysics & 70 & $34+15+21$ & 6 \\
Social Medicine & 25 & $15+10+0$ & 2 \\
Anatomy & 200 & $60+70+70$ & 20 \\
Histology and Embryology & 110 & $30+40+40$ & 10 \\
Clinical and Social skills I & 85 & $10+5+70$ & 3 \\
Research in Biomedicine and Health I & 50 & $10+15+25$ & 4 \\
Elective course (two) & 50 & $10+20+20$ & 4 \\
\hline \multicolumn{1}{c}{ Total } & 715 & & 60 \\
\hline
\end{tabular}

\begin{tabular}{|c|c|c|c|}
\hline \multirow{2}{*}{$\begin{array}{l}\text { YEAR } 2 \\
\text { Subject }\end{array}$} & \multicolumn{2}{|l|}{ Hours } & \multirow{2}{*}{ ECTS } \\
\hline & Total & $L+S+P$ & \\
\hline Medical Chemistry and Biochemistry & 190 & $50+80+60$ & 17 \\
\hline Research in Biomedicine and Health II & 25 & $0+10+15$ & 2 \\
\hline Physiology & 170 & $19+95+56$ & 15 \\
\hline Immunology and Medical Genetics & 90 & $24+42+24$ & 6 \\
\hline Basic Neuroscience & 95 & $21+42+32$ & 9 \\
\hline Clinical and Social skills II & 85 & $10+5+70$ & 3 \\
\hline Medical Humanities II - History of Medicine and Social Responsibility of Medicine & 50 & $20+30+0$ & 4 \\
\hline Elective courses (two) & 50 & $10+20+20$ & 4 \\
\hline Total & 755 & & 60 \\
\hline
\end{tabular}

\begin{tabular}{|c|c|c|c|}
\hline \multirow{2}{*}{$\begin{array}{l}\text { YEAR } 3 \\
\text { Subject }\end{array}$} & \multicolumn{2}{|c|}{ Hours } & \multirow{2}{*}{ ECTS } \\
\hline & Total & $\mathrm{L}+\mathrm{S}+\mathrm{P}$ & \\
\hline Basics of Medical Microbiology and Parasitology & 80 & $12+20+48$ & 7 \\
\hline Research in Biomedicine and Health III & 25 & $0+10+15$ & 2 \\
\hline Pathology & 180 & $40+70+70$ & 16 \\
\hline Psychological Medicine I & 30 & $10+10+10$ & 2 \\
\hline Patophysiology & 110 & $40+40+30$ & 9 \\
\hline Pharmacology & 115 & $25+50+40$ & 10 \\
\hline Clinical propedeutics & 180 & $45+45+90$ & 8 \\
\hline Medical Humanities III - Communication Skills & 25 & $10+15+0$ & 2 \\
\hline Elective course (two) & 50 & $10+20+20$ & 4 \\
\hline Total & 795 & & 60 \\
\hline
\end{tabular}


Table 1, continued

\begin{tabular}{llll}
\hline YEAR 4 & \multicolumn{2}{l}{ Hours } & \multirow{2}{*}{ ECTS } \\
\hline Subject & Total & L+S+P \\
\hline Radiology & 70 & $20+10+40$ & 4 \\
Nuclear Medicine & 30 & $10+8+12$ & 2 \\
Internal Medicine & 360 & $72+72+216$ & 20 \\
Infectology & 75 & $15+20+40$ & 5 \\
Clinical microbiology and parasitology & 30 & $12+18+0$ & 2 \\
Psychological Medicine II & 30 & $10+10+10$ & 2 \\
Neurology & 85 & $20+25+40$ & 6 \\
Neurosurgery & 15 & $4+6+5$ & 1 \\
Psychiatry & 105 & $30+20+55$ & 6 \\
Dermatovenerology & 80 & $20+20+40$ & 5 \\
Medical Humanities IV - Medical Ethics and Bioethics & 50 & $10+40+0$ & 3 \\
Research in Biomedicine and Health IV (parallel with selected clinical courses) & 25 & $0+10+15$ & 2 \\
Elective course & 25 & $5+10+10$ & 2 \\
\hline \multicolumn{1}{c}{ Total } & 980 & & 60 \\
\hline
\end{tabular}

\begin{tabular}{|c|c|c|c|}
\hline \multirow{2}{*}{$\begin{array}{l}\text { YEAR } 5 \\
\text { Subject }\end{array}$} & \multicolumn{2}{|c|}{ Hours } & \multirow{2}{*}{ ECTS } \\
\hline & Total & $\mathrm{L}+\mathrm{S}+\mathrm{P}$ & \\
\hline Anaesthesiology and Intensive Medicine & 95 & $15+20+60$ & 5 \\
\hline Surgery & 205 & $36+54+115$ & 13 \\
\hline Urology & 40 & $10+10+20$ & 2 \\
\hline Ophthalmology & 60 & $15+15+30$ & 4 \\
\hline Otorhinolaringology & 70 & $15+20+35$ & 4 \\
\hline Maxillofacial surgery and Dental Medicine & 30 & $10+10+10$ & 2 \\
\hline Orthopaedics & 55 & $10+20+25$ & 3 \\
\hline Physical and Rehabilitation Medicine & 45 & $13+16+16$ & 2 \\
\hline Gynaecology, Obstetrics and Reproductive Medicine & 200 & $50+50+100$ & 12 \\
\hline Clinical Oncology & 30 & $5+10+15$ & 2 \\
\hline Occupational and Naval Medicine with Environmental Health & 60 & $20+20+20$ & 3 \\
\hline Research in Biomedicine and Health V & 25 & $0+10+15$ & 2 \\
\hline Medical Humanities V - Clinical Ethics & 25 & $9+16+0$ & 2 \\
\hline Epidemiology & 60 & $33+11+16$ & 4 \\
\hline Total & 1000 & & 60 \\
\hline
\end{tabular}


Table 1, continued

\begin{tabular}{|c|c|c|c|}
\hline YEAR 6 & Hours & & ECTS \\
\hline Subject & Total & $L+S+P$ & \\
\hline Forensic Medicine & 60 & $10+26+24$ & 3 \\
\hline Paediatrics with School Age Medicine & 215 & $56+64+95$ & 14 \\
\hline Laboratory Diagnostics & 40 & $10+10+20$ & 3 \\
\hline Health care organization and health economics & 75 & $40+20+15$ & 3 \\
\hline Medical Humanities VI - Ethics of Palliative Medicine & 25 & $0+25+0$ & 2 \\
\hline Research in Biomedicine and Health VI (Diploma thesis) & 120 & $2+6+112$ & 7 \\
\hline Family Medicine & 80 & $20+60$ & 3 \\
\hline Clinical rotation: Family Medicine & 100 & C. rotation & 4 \\
\hline Clinical rotation: Internal Medicine & 180 & C. rotation & 7 \\
\hline Clinical rotation: Surgery & 180 & C. rotation & 7 \\
\hline Clinical rotation: Mother and Child & 180 & C. rotation & 7 \\
\hline Total & 1255 & & 60 \\
\hline
\end{tabular}

* $\mathrm{L}$ - lectures, $\mathrm{S}$ - seminars, $\mathrm{P}$ - practicals. † European credit transfer system.

\section{Decisions that we had to make}

A careful and objective analysis of the academic programs for Medicine in Europe, shows a surprising variety of programs, so vast that it is impossible to find a standard curriculum (14). Instead, we had the option of either copying the curriculum developed by a prestigious medical school or adopting the parts of individual programs which seemed best applicable to our own environment and make a "happy mix" of several different programs. We opted for the latter approach, keeping in mind the major weaknesses of our school, primarily the insufficient number of academic staff members, and secondly the lack of tradition and expertise in some contemporary approaches to medical training, such as "problem-based learning" (PBL) or complete structuring of preclinical curriculum to "organ oriented" organization of the course. In the case of these two concepts, the development of PBL is expected in a year or two as part of elective courses, whereas "organ oriented" teaching is emphasized in clinical subjects.

\section{The framework of the curriculum for the Medical School in Split}

In accordance with the Provisions of Directive 2005/36/EC of the European Parliament and the European Council on recognition of professional qualifications (from 7 September 2005) (15) and its amendments, our program redefines the competencies of a medical graduate by taking into account our original teaching experiences and modern trends in medical education. Recommendations from Article 27 of the Regulated Professions and Recognition of Foreign Professional Qualifications Act are specifically applied:

Training for medical doctors guarantees that the student acquired the following knowledge and skills:

- Adequate knowledge of basic sciences on which medicine is based on and a good understanding of scientific methods including the principles of biological functions and evaluation of scientifically established facts and data analysis.

- Sufficient understanding of structure, function and behaviour of healthy and sick 
individuals as well as the interrelation of a person's health with his physical and social environment.

- Adequate knowledge of clinical disciplines and procedures giving an integrated image of both mental and physical illnesses, of medicine in general, from prevention to diagnosis and therapy, including human reproduction,

-Adequate clinical experience gained in health care facilities under appropriate supervision

Our curriculum particularly recognizes the need for increasing the level of clinical skills of medical graduates and this has been emphasised in the program. Basic elements of internship are also incorporated into the sixth year of the curriculum as so called "clinical rotations". Choice of this form of teaching organisation is based on the perception of medical education as the source of a) knowledge, b) skills and c) attitudes, in which the teaching units, at the end of the program, integrate previously acquired knowledge, skills and attitudes into a professional care for the patient. Knowledge and skills are gained gradually during the program to be finally integrated in clinical rotations.

\section{Specific features of the program}

Firstly, in the first two years new subjects called Clinical and social skills I and II were introduced, so that in conjunction with so called "clinical propedeutics" (in the third year), classical clinical subjects and clinical rotations lead to gradual acquisition of skills, beginning with practising on anatomical preparations then using models (phantoms) and finally in the context of hospital wards with real patients. Clinical and social skills I and II gained the status of obligatory subjects with ECTS points, and teaching was organised in allocated classrooms fitted with all the necessary equipment.
According to the latest European and American trends, a Medical humanities course was introduced (16), and vertically integrated through all six study years. This course includes Introduction to Medicine, Medical Sociology, Medical Ethics, History of Medicine, and Medical Humanities in the narrow sense. Introduction of "Medical Humanities" into the Medicine curriculum is considered to be one of the latest achievements of medical education, introduced with the intention of expanding the physician"s worldview, "softening" heavily structured and specific programs with the aim of stimulating empathy in future physicians towards their patients $(17,18)$.

Psychological medicine I and II was expanded during the third and the fourth year of the course, aiming to prepare students for challenges related to direct contact with (demanding and difficult) patients.

Following recommendations of the World Federation for Medical Education (19) the vertically integrated subject Research in Biomedicine and Health was introduced. It contains courses from the old program: Introduction to Research in Medicine, Medical Statistics, and Medical Informatics. It has been expanded with new topics including: Principles of Evidence Based Medicine (EBM), Evaluation of Health Care Excellence and finally by conducting a research project resulting with production (and defence) of a research thesis (20). From the first year, students are introduced to the principles of evidence-based medicine and are instructed to constantly use that concept in learning and practice so it can be adopted as a "way of thinking" for each medical student. Stanford University School of Medicine's strong commitment to student research is founded on the principle that investigative experience sharpens critical reasoning (21). Students who are educated in a research environment are stimulated to seek so called "deeper understanding" of disease 
and develop their ability to analyse scientific literature, making them valued members of any medical field, whether it be academic medicine, community-based practice, health care policy or emerging technologies (21). We were guided by the belief that the practice of medicine requires education in scientific principles, acquisition of knowledge, as well as an understanding of how current medical knowledge is scientifically justified and how that knowledge changes.

Family Medicine changed to a subject with a relatively small portion of teaching hours allocated to lectures/seminars and a strong focus on practical work/clerkship in primary care environment in both city and country/suburban practices.

Medical genetics was modernized towards bioinformatics, genomics and proteomics and is with Immunology "integrated" into a single subject and a single exam.

A new course, Medical Diagnostics, was introduced in the final year, since even routine medical diagnosis is accompanied with complicated "personalised" diagnostic procedures (e.g. genomics, bioinformatics, proteomics, and individualized medicine).

\section{What are "Clinical rotations?"}

Using the idea of professional apprenticeship, a new form of teaching/learning (which basically replaces the former internship) was introduced with the aim to provide each student with the unique experience of independent-but-supervised professional training in the final year of the medical course. Rotations are shaped so that students can integrate acquired knowledge and skills and apply them to everyday work on patients. Rotations are: Internal Medicine, Surgery, Maternal and Child Health and Family Medicine, with 640 hours divided between these four rotations. Students are guided by their clinical supervisors in a one-to-one fashion.
Within the clinical rotations in Internal Medicine, Surgery and Maternal and Child Health students are given the choice of subspecialties (e.g. neurology in Internal Medicine rotations) while in Family Medicine they can experience working in a specific environment (city, countryside, island etc.). Supervisors are chosen from senior residents and junior ward physicians. Their only mission is to make their student-protégé a close follower of their work and their substitute, whenever that is possible.

\section{Openness of the program towards student mobility and diversity of extracurricular activities}

In addition to taking elective courses that are a formal part of the School's program, students can satisfy requirements for an elective course in the following way: 1) by spending time, during the summer holidays, in a hospital or research laboratory abroad; 2) by volunteering in social institutions; 3 ) through Erasmus programs and schemes (if student's work under this program lasts for two months or more, he/she will be acknowledged up to two elective subjects); 4) through publication of a scientific article (coauthorship on a research paper published in a scientific journal, which is not used in the final thesis); 5) active participation in educational activities of the Croatian branch of the Italian Cochrane Centre (CBICC), active participation in CroCoS seminars (annual CBICC meeting) and successfully completed electronic CBICC course is also acknowledged as an elective course.

\section{Additional exams that students want to sit!}

New exams have been introduced, similar to the German schools of medicine "rigoroz", "physicum", and the United States Medi- 
cal License Examination (USMLE) 1, 2 and 3. Our exams are named "Comprehensive exam 1" (CE1 at the end of the third year of study and include all subjects from the first three "preclinical" years), Comprehensive exam 2 (CE2 at the end of the sixth year, including all clinical subjects) and an Objective Structured Clinical Examination (OSCE) also at the end of the sixth (final) year. Their purpose is the control (or restriction) of inconsistent and spasmodic studying, "scraping by" in exams and elimination of cheating in exams. We also wanted to create the possibility of a Gaussian distribution of students according to their performance, which is why these exams are strongly represented in the Diploma Supplement. An important dimension of this novelty is feedback on the quality of teaching of certain subjects as well as a chance to evaluate credibility of grades that students obtain.

\section{Our curriculum has well defined boundaries}

Our new program insists on strict compliance with the Bologna rules, guidelines and principles in accordance with the Regulations on the study and studying at the University of Split and School of Medicine in Split. This means that the school year runs from 1 October to 15 July, so that the prescribed number of hours of the program (5500) could be accomplished without compromising the recommendation that a student should have no more than 25-30 hours of direct teaching/instructions in one week. The year is not divided into semesters, and classes are conducted in blocks (cycles) for individual subjects. The first examination period is scheduled after the completion of lessons (cycles or blocks), after several free/ study days (counting weekends and holidays). This interval is determined in proportion to the length of the block of a subject to which it refers. The second examination period is between 16 and 31 July, while the third and fourth examination periods are in September. The fourth examination period is always in front of an examination committee. In the case of unsatisfactory results (even after four attempts), a student has to re-enroll the subject.

\section{Conclusion}

It appears that a constant evolution (sometimes even a revolution) of medical curricula is driven by several major reasons: an exponential expansion of the amount of knowledge in biomedical sciences, changing "character" of contemporary medical practices and a strong push to educate and train practitioners with built-in problem solving/ critical thinking skills in addition to the evidence-based professional mind-set. Our political and socio-economic realities leaning on (often restraining) traditional and cultural values do not allow major shifts in curricular designs, particularly in biomedical and health-related tertiary education. Our delay in introducing revolutionary curricular changes may not necessarily be bad, many forms of PBL-based curriculum did not pass the test of time (or financial sustainability) resulting with several iterations of the original "McMaster PBL" curriculum design; the latest adopted in 2005 is called COMPASS (concept-oriented, multidisciplinary, problem-based, practice for transfer, simulations in clerkship, streaming) model focusing on logical sequencing of basic/clinical concepts and the organisation of body systems (22).

We believe that one of the ways to address demands to reorganise the curriculum according to the latest recommendations is vertical integration of as many subjects/ disciplines as possible. When this is done, a set of core problems/principles for every subject can be developed and followed, from early to late years, from simple to more complex concepts, from preclinical to clinical 
scenarios and settings. This creates clear opportunities for students to not just gain basic/clinical knowledge but also to apply it to real clinical problems. For start, our vertical integration effort included medical humanities, principles of research in biomedicine, to a smaller degree psychological medicine and, perhaps most importantly, clinical and social skills. We believe that this approach should be adopted for subjects like pathology and pharmacology, for which a set of common principles could be applied to most if not all clinical problems and scenarios. Sub-specializing pathologists and clinical pharmacologists are already members of a wide range of clinical teams and their experiences should be incorporated into the core medical curriculum (within "classic" medical and surgical clinical subjects) in the form of clinicopathological/pharmacological case conferences or debates (23). Not a single innovation or intervention in the curriculum should pass without careful evaluation and monitoring, in which both students and teachers have equal say. In addition to this, we believe that student"s knowledge, skills and attitudes should be monitored and continuously assessed with exams which are not part of the compulsory set of subjects. Hence we introduced so called "Comprehensive exams 1 and 2" as well as an end-ofcourse OSCE. Results of the first Comprehensive exam 1 held in September 2011 are very encouraging with all but one student out of 58 achieving more than $60 \%$ of correct answers.

Introduction of changes and novelties always meet a lot of resistance and scepticism from both parties involved in the education process (students and teachers), but as long as they are based on solid educational research, on continuous assessment and evaluation and is financially sustainable it should gain both encouragement and support of the faculty administration.
Authors' contributions: All three authors authored the described curriculum, drafted and revised the manuscript and approved of its final version.

Conflict of interest: The authors declare that they have no conflict of interest. This article was not sponsored by any external organisation.

\section{References}

1. Marusic M. History of School of Medicine in Split In: Jankovic S, Boban M, editors. University of Split, School of Medicine, 1997-2007. Split: University of Split School of Medicine, 2007. p. 17-35.

2. Marusic M. On the advancement of science in developing countries: an example of seventy croatian young scientists educated in Germany and USA. Croat Med J. 1996;37(4):273-82.

3. Marusic M. War and medical education in Croatia. Acad Med. 1994;69(2):111-3.

4. Marusic A. Revitalization of academic medicine: looking into the future. Croat Med J. 2005;46(1):1-3.

5. Awasthi S, Beardmore J, Clark J, Hadridge P, Madani $\mathrm{H}$, Marusic A, et al. Five futures for academic medicine. PLoS Med. 2005;2(7):e207.

6. Novak K, Miric D, Jurin A, Vukojevic K, Aljinovic $\mathrm{J}$, Caric A, et al. Awareness and use of evidencebased medicine databases and Cochrane $\mathrm{Li}$ brary among physicians in Croatia. Croat Med J. 2010;51(2):157-64.

7. Final Report of the Commission on Medical Education. California and western medicine. 1933;38(2):112-3.

8. Swanson AG, Anderson MB. Educating medical students. Assessing change in medical educationthe road to implementation. Acad Med. 1993;68(6 Suppl):S1-46.

9. WFME task force on defining international standards in basic medical education. Report of the working party, Copenhagen, 14-16 October 1999. Med Educ. 2000;34(8):665-75.

10. International standards in medical education: assessment and accreditation of medical schools educational programmes. A WFME position paper. The Executive Council, The World Federation for Medical Education. Med Educ. 1998;32(5):549-58.

11. Grkovic I. Transition of the medical curriculum from classical to integrated: problem-based approach and Australian way of keeping academia in medicine. Croat Med J. 2005;46(1):16-20.

12. Croatian Parliament. Zakon o reguliranim profesijama i priznavanju inozemnih stručnih kvali- 
fikacija. Zagreb: Narodne Novine. 2009; 124/09. Available from: http://narodne-novine.nn.hr/ clanci/sluzbeni/2009_10_124_3045.html Accessed: January 03, 2012.

13. Sapunar D. The Medical School of Split-overview of its activity from independence until today. Lijecn Vjesn. 2001;123(9-10):221-30.

14. Dusek T, Bates T. Analysis of European medical schools' teaching programs. Croat Med J. 2003;44(1):26-31.

15. EUR-lex. Directive 2005/36/EC of the European Parliament and of the Council of 7 September 2005 on the recognition of professional qualifications 2005. Available from: http://eur-lex. europa.eu/LexUriServ/LexUriServ.do? uri= CELEX:32005L0036:en:NOT Accessed: January 03, 2012.

16. Wershof Schwartz A, Abramson JS, Wojnowich I, Accordino R, Ronan EJ, Rifkin MR. Evaluating the impact of the humanities in medical education. Mt Sinai J Med. 2009;76(4):372-80.

17. Lindgren S, Karle H. Social accountability of medical education: aspects on global accreditation. Med Teach. 2011;33(8):667-72.
18. Banaszek A. Medical humanities courses becoming prerequisites in many medical schools. CMAJ. 2011;183(8):E441-2.

19. Education WFfM. Basic Medical Education: WFME Global Standards for Quality Improvments. In: 2003 WOUoCD, 2003. Available from: http://www.iaomc.org/wfme.htm Accessed: January 03, 2012.

20. Marusic A, Marusic M. Teaching students how to read and write science: a mandatory course on scientific research and communication in medicine. Acad Med. 2003;78(12):1235-9.

21. Laskowitz DT, Drucker RP, Parsonnet J, Cross PC, Gesundheit N. Engaging students in dedicated research and scholarship during medical school: the long-term experiences at Duke and Stanford. Acad Med. 2010;85(3):419-28.

22. Neville AJ, Norman GR. PBL in the undergraduate MD program at McMaster University: three iterations in three decades. Acad Me.d 2007;82(4):370-4.

23. Wittert GA, Nelson AJ. Medical education: revolution, devolution and evolution in curriculum philosophy and design. Med J Aus. 2009;191(1):35-7. 